\title{
SMMES Oriented Craft File Design and Management: WAMP Applied
}

\author{
Wenjia Duan, Xiangji Li, Xiaowei Liu and Wenjun Hou \\ Automation School, Beijing University of Posts \& Telecommunications, Beijing 100876, \\ China gavin0590@gmail.com diysimon@gmail.com tiemeng2000@gmail.com \\ wenjunh2113@263.net
}

\begin{abstract}
The process of craft file design and management, which varies a lot in different areas and enterprises, is the most important part of design process in Small and Middle-sized Manufacturing Enterprises (SMMEs). The Design and Management System of such processes is required to be highly customized due to their complexity and lack of flexibility. In this paper, we presented a simple SMMEs oriented Craft File Design and Management system based on Web3D\&X3D, Apache, MySQL and PHP (WAMP), which are free and open source. The system is $\mathrm{B} / \mathrm{S}$ structured and focuses on the $3 \mathrm{D}$ design file sharing on web, craft file distributing and collaboration according to specified process. The system is deployed in our cooperating company and proved to be able to lower design costs and improve efficiency.
\end{abstract}

Keywords: EIS for manufacturing sector, Manufacturing planning and execution, Open source, WAMP

\section{PRELIMINARIES}

\subsection{WAMP}

WAMP is a form of application framework that can run on almost any windows operating systems. It's a Microsoft windows-based variant of LAMP. LAMP is a framework composed of Linux, Apache, MySQL and PHP/Perl/Python. Comparing to LAMP, WAMP is composed of Windows, Apache, MySQL and PHP/Perl/Python. The major difference between them is that they are running on totally different operating systems. In this paper, WAMP stands for a web-based application framework which is running on windows, using Apache as HTTP server, MySQL as database and PHP as script language. 


\subsection{Craft Design}

Craft design is part of product design. It mainly evolves with the manufacturing section. The task of craft design is to evaluate manufacturability of a set of parts and then find a process to manufacture and assembly them. Craft files are the technical files that describe processes of manufacture. In mechanical manufacturing area, craft files can always be divided into part craft files and assembly craft files. In this paper, craft design is discussed in mechanical manufacturing area.

\subsection{B/S Architecture}

$\mathrm{B} / \mathrm{S}$ (Browser/Server) is a popular client-server computing architecture which uses browser as client. In this paper, servers include webserver (Apache), databaseserver (MySQL).

\section{INTRODUCTION}

Craft Design and craft file management is the most important part of design work in manufacturing enterprises. Comparing to big, well-managed and professional manufacturing enterprises, Small \& Middle-sized Manufacturing Enterprises (SMME) is required to be more flexible, effective and creative. Because of the complexity of craft design, its process varies a lot according to different areas and products. Unfortunately, the pursuit of agility and creativity makes it more and more complex and lack of flexibility. Usually, it takes about 9 months for SMMEs to put their new products on the market. During those 9 months, prototype design, trial production and massive production must be finished. What craft designers should complete is to interpret the prototype design and write craft files to instruct real production. To finish it effectively, craft designers must be able to access design data like: 3D design model, standard parts data, tolerance data and production data like: statistics, fast and conveniently. In the traditional way, craft designers use paper documents and blueprints to pass design data through different departments, which it's very easy to cause delay, distortion or loss of information. Accordingly, modern ERP and PDM systems are difficult to employ in SMMEs because they are expensive and usually just too large and complicated for SMMEs.

\subsection{Problem Description}

As the connection between design and manufacture, craft designers must consider not only design data: like part feature, size, tolerance, material but also manufacturing achievements, machine condition, costs and man-hour or even traditional habits etc. According to some survey, EIS for craft design is much worse than that for prototype design and manufacture.

From blueprints to the craft file for instructing real manufacturing, design data is resolved, regrouped, and transformed in different ways and in different mediums. In 
the traditional way, designers use paper blueprints and pass them through departments. It's slow and lack of efficiency. In a word, the craft file design and management system for SMMEs should solve the problems as below:

1. Integration with main $\mathrm{CAD}$ software similar to large commercial software.

2. Fast and precious control on design data transfer.

3. Highly customize for different process.

In this paper, we proposed a highly customized craft file design and management system according to the study of Small \& Middle heavy machine manufacturing enterprises and made useful research on craft file management, collaboration, 3D file sharing and visualization.

\section{SYSTEM DESCRIPTION}

To integrate closely with specified process of craft design, we proposed a system based on WAMP to solve the problems as follows: integration with $\mathrm{CAD}, 3 \mathrm{D}$ model sharing and visualization, craft file management. The system was B/S structured, as described in fig1:

\subsection{Application Architecture}

The system was composed of one server and many browsers. The browsers were distributed in the enterprises and could collaborate with each other. The server was composed of a HTTP server and a database server. This multi-tiered architecture made our system more scalable and flexible. In our implement, we chose Apache as the HTTP server and MySQL as database server. As the most stable HTTP server, Apache has been running on $65 \%$ of web servers worldwide and MySQL can also provide steady and fast data access service as the most popular open source relational database.

According to the $\mathrm{B} / \mathrm{S}$ architecture, data and files were managed on the server, which helped to make centralized configuration and management on resources, to make statistics and to keep synchronization. The servers were running on windows but linux due to the reasons as follows:

1. Operating systems running in SMMEs are mostly Microsoft windows. It's hard for SMMEs to construct another system running on Linux and hire more professional staffs for its maintenance. Choosing Linux will get rid of license costs, but it will increase costs on hiring staffs and risk on compatibleness.

2. Considering integration with front $\mathrm{CAD}$ systems, $\mathrm{CAD}$ software mostly deployed in manufacturing enterprises is still unavailable on LINUX.

3. AMP (Apache, MySQL, PHP) based on windows has been paid more and more attention by Microsoft and other software suppliers. WAMP is easier to deploy on now-existing systems in SMMEs and on the other hand, it can also make use of the advantage of open source software. 


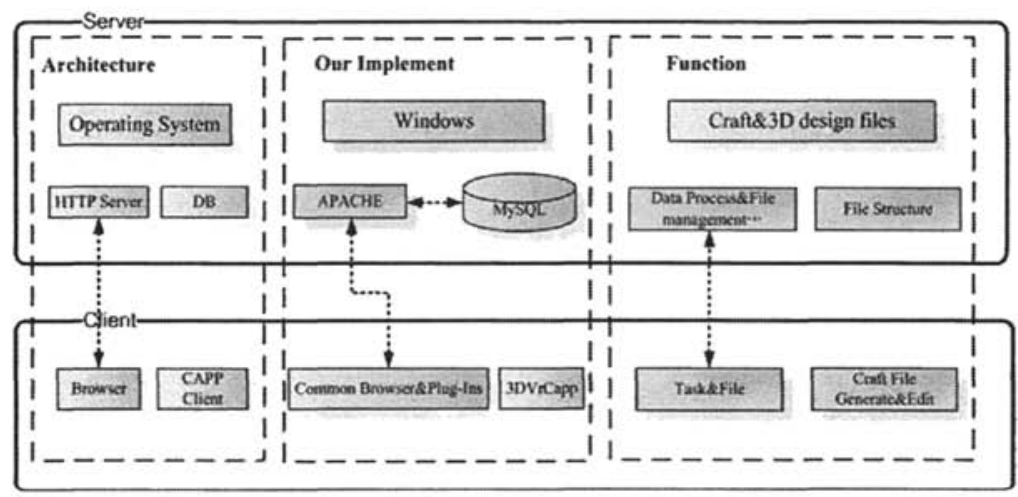

Figure 1. System Architecture

\subsection{Functional Architecture}

Data process and file management were completed on the server. On the browsers, functions like: 3D model visualization, craft file sheet template generation, were completed by executing PHP web page. To view the 3D model interactively, additional plug-ins were required.

What should be paid attention is that: Craft file design is not finished on the browser. It's implemented in another CAPP module. The module is developed from a former single user application. By moving the database from local machine to the server, the module is integrated with the file management system. Though this design breaks the B/S structure, we stuck to it based on the consideration as follows:

1. The function implemented in the CAPP module is hard to achieve on the browser.

2. Using now-existing system provide better compatibleness.

\section{SYSTEM IMPLEMENT}

\subsection{Craft Design: Integrate with CAD\&CAPP}

To integrate with front CAD system, an effective way was to perform redevelopment in CAD systems. But it could not be used in our $\mathrm{B} / \mathrm{S}$ structured system because CAD models cannot be inserted into browsers. To solve this problem, we used the intermediate file: X3D to carry and transfer 3D design data. As the successor to the VRML and VRML 97, X3D files can be easily transferred between server and browser. By installing additional plug-ins, 3D models can be accessed interactively. But extracting data from preciously defined CAD model to triangle-strip based VRML files would lose some important information: assembly architecture, mate information and material information. This section discusses on information extraction from CAD models. 


\subsubsection{D Files Management: Sharing and Visualization}

By integrating with front CAD system, we provided both part view and assembly view, which based on $\mathrm{X} 3 \mathrm{D}$, as described in figure 2 :

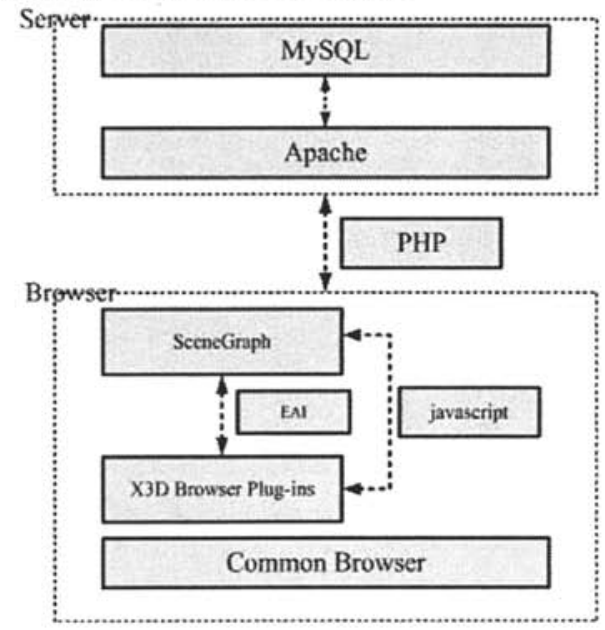

Figure 2. 3D Model Visualization

To implement the assembly view, using multi-level assembly tree of text format is the easiest way. Though it has less information, it's fast. By combing with part ID (a number to identify very part), user could quickly access 3D models, as shown in figure 3:

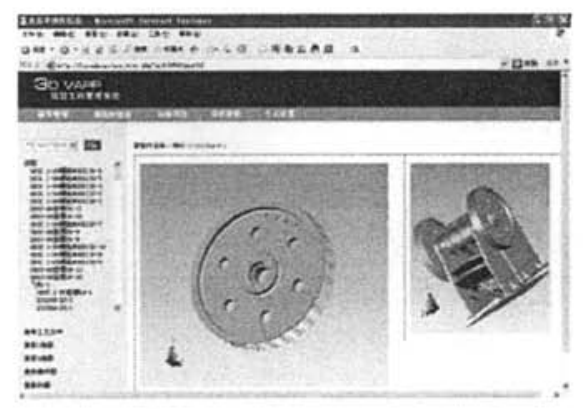

Figure 3. Example of 3D Model Visualization

Sole text-formated assembly tree would be just not enough. Here we provided an interactive way. By setting a $3 \mathrm{D}$ model of the whole product view, user could select his/her interested part by clicking in the whole product view and the part view will be changed to the part selected. The approach was implemented by EAI and javascript. By getting the coordinates user clicks, we could decide which part the point (actually a line) interferes with through EAI, and then refresh the part view. 
Actually, the platform shown above was just suitable for 3D model viewing and management and it is not fit for craft file design which needs many interactive operations and file editing. Here, we used the CAPP client called 3DVrCapp which was developed from the former application for single user. The client was running on the local machine and was able to download specified 3D models from the server. The version control mechanism will make sure that the checked files were released.

\subsection{Craft File management: Process and Collaboration}

Craft design is a highly distributed process that requires collaboration of many departments. This section discusses on project-driven engineer collaboration and resource management.

\subsubsection{Project Collaboration: Privilege and Organize}

The project driven collaboration requires that resources are organized based on projects, that is: design resources are bind to project, staffs are organized in projects, and tasks are assigned according to projects. Usually, companies are organized as rooted trees. The tree has only one root, standing for the company. The children beneath it are department manager. The lowest children are the staffs. Such kind of organization is lack of flexibility and is not fit for variable projects.

Organization based on projects usually use matrices to describe the relationship of the staffs in the project. The matrix has two dimensions: duty and Project. Here is an example as shown in Table 1:

The duty determines the tasks specified staff will have to finish in one project. On staff can take different role in different projects and there may be many staffs of the same role in a project.

When a project is carrying on, different kinds of resources are assigned, collect and regroup. Staffs having different duties have different privilege on resources. How resources are organized determines how privilege is managed, that is: the user, role, privilege mode.

- User: stands for the staff completing specified tasks

- Role: group of users that has specified duty

- Privilege: privilege is bind to resources, for example, the edit privilege of a document, the release privilege of a craft file, etc.

Sole privilege has no effect. It must be bound to specified resources, which is called the instantiation of privilege. After the instantiation, resources can be assigned to users with specified privilege. Usually, types of privilege are decided $s$ when the platform is designed.

There are two ways to bind privilege instance to the users. One is binding it directly to the very user, and the other binding it to roles. Here, the latter was used based on the consideration as follows:

1. Privilege is related to the duty in a project

2. There may be many users having the same duty

3. One user may have different duties in different projects. 
The privilege managing module implemented in our system preset five privileges: resource check, user check, resource view and resource release. The module had also preset a role: administrator which could create new roles and bind privilege to roles.

\subsubsection{Engineer Collaboration; File Management and Version Control}

In the multi-user environment, files of different types like X3D, Excel, Word and pictures etc, are accessed and edited by many users. This section discusses that how files were managed and how the file version control mechanism were implemented.

The data craft accessed by designers during craft design is usually based on the assembly hierarchy of the product. Files like craft documents, blueprints for assembly, blueprints for parts are always organized like trees similar to the assembly tree. In our system, files were bound to the public database according to the assembly tree. But there were a few differences when treating part craft design and assembly craft design. Assembly craft design focuses on how the parts are assembled and craft file are always related to the root nodes in the assemble tree. While part craft design focuses on the part manufacture. To simplify the design, parts of the same part will be grouped. As a result, we provided two kinds of views: part view and assembly view.

Multi-User collaboration with files requires version control mechanism. The version control module implemented in our system could be described as Check out, Check in and Release.

- Check out: users with specified privilege get the file it needs from server, which are now released.

- Check in: users upload files edited to the servers, waiting for check.

- Release: After checking and dealing with conflicts, files are released and available to check out.

The version control mechanism was combined with privilege management. After a file was checked out, the privilege bound to the file would be changed and the file was prohibited to be edited unless the file was checked in. After check in, a file of new version was generated. So users could easily roll back to the early version of the file if necessary. But the drawback is that it may cause expanding of the amount of files. Every file checked in would be checked and released according to the role bound to it, which ensures that the file available for checking out was correct.

\section{SYSTEM TEST AND RESULTS}

The system was deployed in our cooperating company and a simple test was carried out. The test was carried on the same condition as described in 5.1.

\subsection{Test Condition}

- Test project: PE600X900.K3127.00

The tests were performed on the same project. 
Table 1. Project Description

\begin{tabular}{|l|l|}
\hline Number of parts & 238 \\
\hline Number of subassembly & 10 \\
\hline Number of blueprints & 238 (part) +12 (subassembly) +10 (fixture) \\
\hline Craft files generated & $238($ part) +12 (assembly) \\
\hline
\end{tabular}

- Test Items: time of getting technical files, error rate of getting files, time of craft design

Time of getting tested how much time it took the craft designers to access design data including blueprints of part or subassembly, standard data, etc. we define the file accessing time as follows:

$$
T_{s}=T_{g}+T_{r}
$$

$\mathrm{T}_{\mathrm{s}}$ : stands for the total time users take to getting the files

$T_{\mathrm{g}}$ : stands for the time users take to find and get the files

$T_{\mathrm{r}}$ : stands for the time users take to return the files if necessary

The error rate of getting files tested the error rate when designers were getting files. The error may caused by similar file names or poor file management (the files were not at the right position).

The time of craft tested how much time the team takes to the finish the project.

- Test Environment

Before deploying our system, the design data in the company were mainly managed by blueprints, paper documents and some craft files were made in Excel.

During the test, all the blueprints of tested project were turned into CAD models and integrated into our system. The time of craft does not include the time to transform the CAD models.

\subsection{Test Result}

Because the tested project had been completed in 3 months in the old way before, to reduce the testing time, we chose only one of the subassembly of project to test the 1 st and 2 nd item. As to the $3 \mathrm{rd}$ item, the project was completed again in our system.

Table 2. Test Results

\begin{tabular}{|c|c|c|c|}
\hline Test Item & Before & After & Rate \\
\hline $\begin{array}{c}\text { Time of getting } \\
\text { files }\end{array}$ & $\begin{array}{c}20 \text { minutes } \\
\text { average }\end{array}$ & $\begin{array}{c}\text { Less than 1 } \\
\text { minute }\end{array}$ & $95 \%$ decrease \\
\hline $\begin{array}{c}\text { Error rate of } \\
\text { getting files }\end{array}$ & $5 \%$ average & Less than 1\% & $80 \%$ decrease \\
$\begin{array}{c}\text { Time of Craft } \\
\text { design }\end{array}$ & 3 months & 2.5 Months & $16.7 \%$ decrease \\
\hline
\end{tabular}

From the result of 1 st item, the time had been remarkably reduced. According to the equation 1 , in our system, $T_{r}$ was always zero because there was no need to return the files. But in the old system, $\mathrm{T}_{\mathrm{T}}$ always takes a lot of time. 
From the result of 2 nd test, the error rate had also been remarkably reduced. Due to the version control mechanism, errors could be easily rolled back. But, because the naming of files in our system still based on its original name which was the same with the old system, it might cause problem when accessing design data.

\section{CONCLUSIONS}

With analysis and modeling of craft design process, we proposed and implemented a system of craft file design and management based on open source software: WAMP. The $\mathrm{B} / \mathrm{S}$ architecture for craft design and file management system was proposed and it was proved to be suitable for craft design. Fine research was also made on version control mechanism and 3D model visualization technology for craft design assistant. The version control mechanism was proved to be able to lower error rate during the test. The system is deployed in our cooperating enterprises and tested to be able to improve efficiency and lower costs.

\section{REFERENCES}

1. T. Alxandre, 3D Visualization of Multimedia Content on the World Wide Web, in Proc. of the 7th International World Wide Web Conference (Brisbane, Australia, April 14-18, 1998).

2. B. Eynard, S. Lienard, S. Charles, and A. Odinot, Web-based collaborative engineering support system: Applications in mechanical design and structural analysis, Concurrent Engineering Research and Applications. Volume 13, Number 2, pp.145-153, (2005).

3. H. Lin, J. Gong and F. Wang, Web-based three-dimension geo-referenced visualization, Computer Geosciences. Volume 25, pp.1177-1185, (1999).

4. Web3D, Virtual Reality Modeling Language, International Standard ISO 14772-11997.

5. W. Hou, Y. Yan, W. Duan, and H. Shun, Research On Three Dimensional Computer Assistance Assembly Process Design System, Journal of Wuhan University of Technology. Volume 28, Number 83, pp.1088-1092, (2006).

6. X3D, Abstract Specification, ISO-IEC-19775.

7. J. Yang and J.S. Kim, Client Browsing module for internet collaborations, in Proc. of the IEEE International Conference on Systems, Man and Cybernetics, Volume 4 (2001), pp.2317-2321. 